\title{
Permeation of Phenothiazines through Cellulose Membrane ${ }^{1,2)}$
}

\author{
Naoki Nambu, ${ }^{3 a)}$ Tsuneji Nagai ${ }^{3 b)}$ and Hisashi Nogami \\ Faculty of Pharmaceutical Sciences, University of Tokyo3)
}

(Received November 6, 1970)

\begin{abstract}
The permeation of phenothiazines through cellulose membrane was investigated as a successive study of the adsorption from aqueous solution reported in a previous paper.

The permeability decreased with the increase in molecular weight of phenothiazines. The activation energy of permeation was close to those of diffusion of usual organic medicinals in water. Any remarkable effect of $\mathrm{pH}$ on the permeation was not observed in the present conditions. It was demonstrated from these results that the permeation of phenothiazines through cellulose membrane proceeds on the basis of a diffusion through pore.

In comparison with the diffusion constant of levomepromazine maleate in aqueous solution evaluated from the dissolution rate by the rotating disk method, the interaction coefficient of the diffusion through cellulose membrane was given as $\mathbf{0 . 4 5 3}$.
\end{abstract}

It has been considered that the mechanism of pharmacological actions of phenothiazines are more or less based on the membrane action or the deposition on the membrane which may be formed of the adsorption on and the penetration into the membrane. In a previous paper,4) as an approach to understanding of the membrane action, the adsorption of phenothiazines from solution was investigated using such adsorbents as carbon black, graphite, silica gel and polyethylene, and it was shown that the adsorbability has relation to such pharmacological activities as neuroleptic and haemolytic ones.

Regarding the membrane penetration of phenothiazines, i.e., another physical process having relation to the membrane action, there has been found very few reports except for Teller and Denber's molecular biological investigation what a structural configuration the molecule may take through the penetration..$^{5}$ The membrane penetration is of kinetical process and thus the investigation of the membrane permeation of phenothiazines may give useful informations for understanding of the membrane penetration.

The present study was attempted to investigate the permeation through cellulose membrane as a successive study of the adsorption from solution reported in the previous paper. ${ }^{4}$ Additionally, the diffusion constant in aqueous solution was obtained from the dissolution by rotating disk method in order to compare with that through the membrane.

\section{Experimental}

Materials_- Phenothiazines used were the same as those in the previous paper. ${ }^{4} \quad$ Visking tubing No. 101 was obtained commercially to prepare the cellulose membrane.

1) This paper forms Part XX of "Physico-chemical Approach to Biopharmaceutical Phenomena." Preceding paper, Part XIX: H. Uneyama, T. Nagai, and H. Nogami, Chem. Pharm. Bull. (Tokyo), 19, 441 (1971).

2) A part of this work was presented at the 90 th Annval meeting of the Pharmaceutical Society of Japan, Sappro, July, 1970,

3) Location: Hongo, Bunkyo-ku, Tokyo; a) Present address: Pharmaceutical Research Laboratory, Tanabe Seiyaku Co., Ltd., Kashima-cho, Higashi-Yodogawa-ku, Osaka; b) To whom communications should be directed.

4) H. Nogami, T. Nagai, and N. Nambu, Chem. Pharm. Bull. (Tokyo), 18, 1463 (1970).

5) D.N. Teller and H.C.B. Denber, "Diseases of the Nervous System," GWAN, Supp., 29, 93 (1968). 
Procedure and Apparatus for the Permeation through Cellulose Membrane-The procedure was according to the usual equilibrium dialysis method using a red-brown glass cell of the same style as used in a previous paper. ${ }^{6)}$ The one compartment (A) contained $10^{-3} \mathrm{M}$ of a drug in $1 / 30 \mathrm{M}$ phosphate buffer solution (pH 6.00 , unless otherwise stated), while the other (B) contained the same phosphate buffer solution only. The assembled cell was shaken mechanically at $30^{\circ}$ (unless otherwise stated) in an incubator (Taiyo M- $1 \mathrm{~N}$ ). It was examined preliminarily that the drugs were satisfactorily stable under the experimental conditions.

Quantitative Determination of Phenothiazines_- This was done according to ultraviolet (UV) absorption method in the same way as described in the previous paper.4)

Measurement of the Thickness of Cellulose Membrane-Immediately after all the samplings were finished, the thickness of the membrane was measured with a Mitsutoyo 109-101 micrometer at 12 different places on the membrane, ${ }^{7)}$ and the mean was obtained as $0.0086 \mathrm{~cm}$ with a very small deviation.

Quantitative Determination of $\mathbf{N a C l}$ and $\mathbf{K C l} \_$This was done according to Fajans' method using fluorescein as the indicator. $\left.{ }^{8}\right)$

Apparatus and Procedure for the Dissolution Study Rotating disk method as described in a previous paper') was employea. The experiment was carried out under the following conditions: the disk of levomepromazine maleate of $3 \mathrm{~cm}$ diameter compressed under 4 ton $/ \mathrm{cm}^{2} ; 200 \mathrm{ml}$ of $1 / 30 \mathrm{M}$ phosphate buffer solution ( $\mathrm{pH} 6.00$ ) at $30^{\circ}$; the rotating velocity of disk at $600 \mathrm{rpm}$.

\section{Result and Discussion}

The permeation of drug through a membrane has been expressed as follows:10)

$$
\begin{aligned}
& \log \left\{\left(C_{0}-2 C\right) / C_{0}\right\}=-(2 P / 2.303 \cdot L) \cdot t \\
& P=f \cdot D \cdot S / V
\end{aligned}
$$

where $C$ is the concentration in compartment $B$ at time $t, C_{0}$ the initial concentration in compartment A, $P$ the permeability constant, $L$ the thickness of the membrane, $f$ the membrane constant, $D$ the diffusion constant, $V$ the volume of solution in the respective compartments, $S$ the effective surface area of membrane.

Theoretically, the permeability constant, $P$, does not vary with the initial concentration, $C_{0}$, as expressed by equation (1). Practically, however, $P$ is known to be influenced by the concentration of solute molecule, and thus it should be described together with the initial concentration, as the diffusion constant is done in International Critical Table. ${ }^{11)}$ In this study, the values of $P$ were obtained for the respective drugs in $C_{0}=10^{-3} \mathrm{M}$ for the convenience of experiment.

\section{Membrane Constant, $\boldsymbol{f}$}

Since the permeation of drug through cellulose membrane is considered to proceed on the basis of a diffusion through pore, ${ }^{6}$ ) the membrane constant, $f$, is calculated from the permeation constant, $P$, obtained for $\mathrm{NaCl}$ or $\mathrm{KCl}$ which has no special interaction with cellulose membrane, assuming that both the diffusion constants in water and through the membrane are the same. ${ }^{12)}$

In this study, the values of $P$ for $\mathrm{NaCl}$ and $\mathrm{KCl}$ were obtained at $18^{\circ}$ and $30^{\circ}$, as shown in Table I, and the resultant mean value of $f$ was given as 0.0562 , which was close to the value obtained by Nakagaki, et al. ${ }^{12}$ )

\section{Permeation of Phenothiazines through Cellulose Membrane}

It was examined preliminarily that the linear relation according to equation (1) was given

6) H. Nogami, T. Nagai, and H. Uchida, Chem. Pharm. Bull. (Tokyo), 17, 176 (1969).

7) H. Nogami, T. Nagai, and T. Sonobe, Chem. Pharm. Bull. (Tokyo), 18, 2101 (1970).

8) Sunao Ato, "Bunseki-Kagaku," Baifukan, Tokyo, 1960, p. 248.

9) H. Nogami, T. Nagai, and A. Suzuki, Chem. Pharm. Bull. (Tokyo), 14, 329 (1966).

10) L.M. Lueck, D.E. Wurster, T. Higuchi, A.P. Lemberger, and L.W. Busse, J. Am. Pharm. Assoc. Sci. $E d ., 46,694$ (1957).

11) National Research Council, U.S.A., "International Critical Table," Vol. V, McGraw-Hill Book Co., Inc., New York, 1929.

12) M. Nakagaki, "Yakubutsu no Seitainai-Iko (Drug Transfer in Biological System)," Nankodo Co., Ltd., Tokyo, 1968, p.16. 
TABle I. Membrance Constant of Cellulose Membrane Evaluated from Diffusion Constant of $\mathrm{NaCl}$ and $\mathrm{KCl}$

\begin{tabular}{ccccccc}
\hline \hline & $\begin{array}{c}\text { Temperature } \\
\left({ }^{\circ} \mathrm{C}\right)\end{array}$ & $\begin{array}{c}\text { Apparatus } \\
\text { (No.) }\end{array}$ & $\begin{array}{c}C o \\
(\mathrm{M})\end{array}$ & $\begin{array}{c}P \times 10^{2} \\
\left(\mathrm{~cm}^{2} / \mathrm{sec}\right)\end{array}$ & $\begin{array}{c}\left.D \times 10^{5} a\right) \\
\left(\mathrm{cm}^{2} / \mathrm{sec}\right)\end{array}$ & $f$ \\
\hline \multirow{2}{*}{$\mathrm{NaCl}$} & 18 & 1 & 0.0503 & 7.22 & 1.26 & 0.0573 \\
& 18 & 2 & 0.0506 & 7.17 & 1.26 & 0.0569 \\
& 30 & 1 & 0.0502 & 9.59 & 1.84 & 0.0521 \\
& 30 & 2 & 0.0503 & 9.36 & 1.84 & 0.0509 \\
$\mathrm{KCl}$ & 18 & 1 & 0.0504 & 9.18 & 1.55 & 0.0592 \\
& 18 & 2 & 0.0502 & 9.42 & 1.55 & 0.0608 \\
& & & & & mean $<f>0.0562$ \\
\hline
\end{tabular}

a) ref. 11

TABle II. Permeability Constants and Diffusion Constants of Phenothiazines through Cellulose Membrane at $30^{\circ}$ a)

\begin{tabular}{lccc}
\hline \multicolumn{1}{c}{ Compound } & $\begin{array}{c}C 0 \times 10^{3} \\
(\mathrm{M})\end{array}$ & $\begin{array}{c}P \times 10^{7} \\
\left(\mathrm{~cm}^{2} / \mathrm{sec}\right)\end{array}$ & $\begin{array}{c}D \times 10^{6} \\
\left(\mathrm{~cm}^{2} / \mathrm{sec}\right)\end{array}$ \\
\hline Anergen & 1.047 & 2.54 & 4.52 \\
Diethazine & 1.023 & 1.98 & 3.52 \\
Promazine & 1.004 & 2.37 & 4.22 \\
Chlorpromazine & 1.010 & 2.19 & 3.90 \\
Triflupromazine & 1.005 & 2.03 & 3.61 \\
Promethazine & 1.019 & 2.36 & 4.20 \\
Alimemazine & 1.016 & 2.34 & 4.16 \\
Levomepromazine & $6.49 \times 10^{-2}$ & 2.10 & 3.73 \\
Methodilazine & 1.007 & 2.25 & 4.00 \\
Perazine & 0.997 & 2.07 & 3.68 \\
Prochlorperazine & 1.005 & 1.99 & 3.54 \\
Trifluoperazine & 1.131 & 1.82 & 3.24 \\
Chlorpromazine sulfoxide & 1.034 & 2.08 & 3.70 \\
Isothipendyl & 1.011 & 2.40 & 4.27 \\
\hline
\end{tabular}

a) $f=0.0562, V=200 \mathrm{ml} . A=\pi \times 2.15^{2}\left(\mathrm{~cm}^{2}\right), L=0.0086 \mathrm{~cm}$ in equation (2)

from the data upto $70-80 \mathrm{hr}$ using anergen. The values shown in Table II were obtained by the measurement for $10 \mathrm{hr}$. Only the value for levomepromazine was obtained in a very low initial concentration because of its low solubility. The present values of $D$ were close to those of phenoxazones reported by Nakagaki, et al. ${ }^{\mathbf{1 3})}$

The relationship between the diffusion constant, $D$, and the molecular weight, $M_{\mathrm{w}}$, is shown in Fig. 1. A deviation of diethazine seemed due to the low permeability because of its large side chain at 10-position. Anyhow, it was concluded that the permeability decreased with the increase in molecular weight. It was described in the previous paper ${ }^{4)}$ that the adsorbed amount on carbon black or graphite increased with the bulkiness of the hydrophobic substituent at 2-position as follows: promazine $<$ chlorpromazine $<$ triflupromazine, while such a bulkiness of the substituent at 2-position was considered to cause a steric hindrance in the permeation.

The temperature dependence of the permeation through cellulose membrane is shown in Table III and Fig. 2. The values of activation energy, $E_{a}$, given from Fig. 2 were shown in Table III, being close to those reported for the diffusion controlled dissolution. ${ }^{\mathbf{9}, \mathbf{1 4})}$

13). M. Nakagaki, N. Koga, and S. Iwata, Yakugaku Zasshi, 82, 1134 (1962).

14) H. Nogami, T. Nagai, and A. Kondo, Chem. Pharm. Bull. (Tokyo), 18, 1185 (1970). 


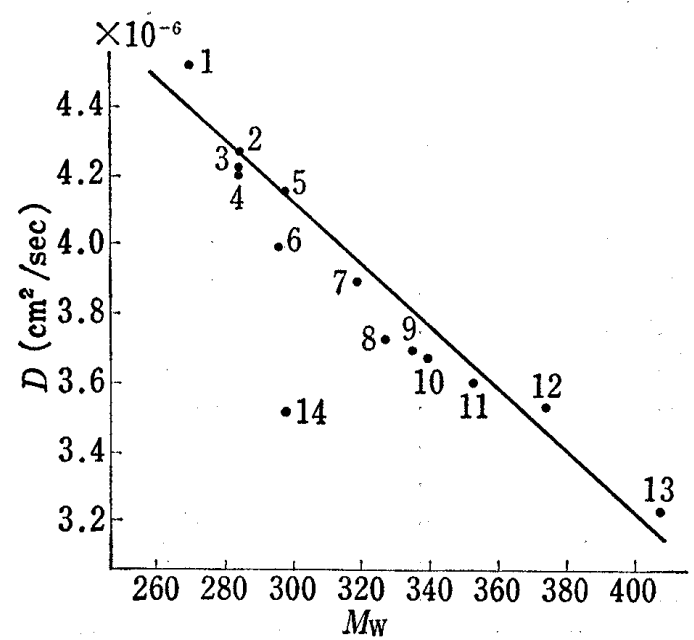

Fig. 1. Relationship between Diffusion Constant through Cellulose Membrane at $30^{\circ}, D$, and Molecular Weight, $M_{\mathrm{w}}$, of Phenothiazines
1. anergen
8. levomepromazin
2. isothipendyl
3. promazine
9. chlorpromazine sulfoxide
4. promethazine
5. alimemazine
. methodilazine
7. chlorpromazine
10. perazine
11. triflupromazine
12. prochlorperazine
13. trifluoperazine
14. diethazine

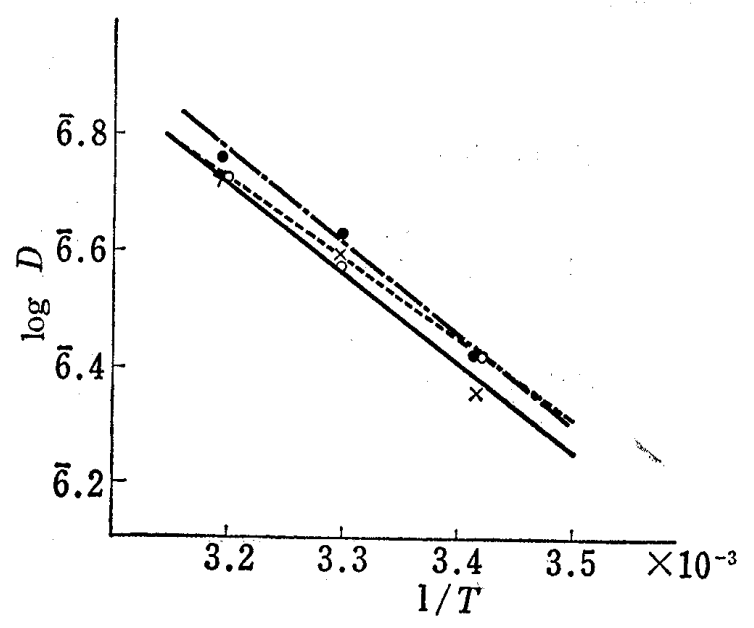

Fig. 2. Temperature Dependences of Diffusion of Phenothiazines through Cellulose Membrane

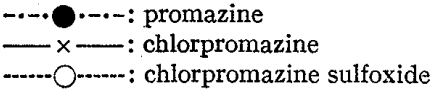

TABle III. Temperature Dependences of Permeability Constant and

Diffusion Constant, and Activation Energy of Permeation of Phenothiazines through Cellulose Membrane ${ }^{a}$ )

\begin{tabular}{|c|c|c|c|c|c|}
\hline Compound & $\begin{array}{c}\text { Temperature } \\
\left({ }^{\circ} \mathrm{C}\right)\end{array}$ & $\underset{(\mathrm{M})}{C_{0} \times 10^{3}}$ & $\begin{array}{c}P \times 10^{7} \\
\left(\mathrm{~cm}^{2} / \mathrm{sec}\right)\end{array}$ & $\begin{array}{c}D \times 10^{6} \\
\left(\mathrm{~cm}^{2} / \mathrm{sec}\right)\end{array}$ & $\begin{array}{c}E_{\mathrm{a}} \\
\text { (kcal/mole) }\end{array}$ \\
\hline \multirow[t]{3}{*}{ Promazine } & $20^{\circ}$ & 1.001 & 1.47 & 2.62 & \multirow{3}{*}{7.15} \\
\hline & $30^{\circ}$ & 1.004 & 2.37 & 4.22 & \\
\hline & $40^{\circ}$ & 1.034 & 3.18 & 5.66 & \\
\hline \multirow[t]{3}{*}{ Chlorpromazine } & $20^{\circ}$ & 1.000 & 1.53 & 2.72 & \multirow{3}{*}{6.86} \\
\hline & $30^{\circ}$ & 1.010 & 2.19 & 3.90 & \\
\hline & $40^{\circ}$ & 1.012 & 2.97 & 5.28 & \\
\hline \multirow[t]{3}{*}{ Chlorpromazine sulfoxide } & $20^{\circ}$ & 1.004 & 1.48 & 2.63 & \multirow{3}{*}{6.40} \\
\hline & $30^{\circ}$ & 1.034 & 2.08 & 3.70 & \\
\hline & $40^{\circ}$ & 1.046 & 2.94 & 5.23 & \\
\hline
\end{tabular}

a) $f=0.0562, V=200 \mathrm{ml}, A=\pi \times 2.15^{2}\left(\mathrm{~cm}^{2}\right), L=0.0086 \mathrm{~cm}$ in equation (2)

Therefore, it was demonstrated by the results in Fig. 1 and 2 that the permeation of phenothiazines through cellulose membrane proceeds on the basis of a diffusion through pore.

Any remarkable effect of $\mathrm{pH}$ on the membrane permeation was not observed in the present conditions as shown in Table IV, indicating that there was no difference in the molecular interaction between the molecules in dissociated state and those in undissociated state. In this connection, the adsorption by carbon black increased with $\mathrm{pH}$ between 5 and 8.4)

\section{Comparison with the Dissolution Rate by Rotating Disk Method}

Levomepromazine maleate is the least soluble among the samples of phenothiazines and thus suitable to the dissolution study by rotating disk method. In the same way as described in the previous paper, ${ }^{9)}$ the dissolution curve was analyzed according to Noyes-Nernst equation (3) and Levich equation (4). 
TABle IV. $\mathrm{pH}$ Dependences of Permeation of Phenothiazines through Cellulose Membrane at $\left.30^{\circ} a\right)$

\begin{tabular}{lcccc}
\hline \hline Compound & $\mathrm{pH}$ & $\begin{array}{c}C_{0 \times 10^{3}} \\
(\mathrm{M})\end{array}$ & $\begin{array}{c}P \times 10^{7} \\
\left(\mathrm{~cm}^{2} / \mathrm{sec}\right)\end{array}$ & $\begin{array}{c}D \times 10^{6} \\
\left(\mathrm{~cm}^{2} / \mathrm{sec}\right)\end{array}$ \\
\hline Promazine & 5.20 & 0.997 & 2.41 & 4.29 \\
& 6.00 & 1.004 & 2.37 & 4.22 \\
Chlorpromazine & 7.00 & 0.918 & 2.18 & 3.89 \\
& 5.20 & 1.017 & 2.23 & 3.97 \\
Chlorpromazine sulfoxide & 6.00 & 1.010 & 2.19 & 3.90 \\
& 7.00 & 1.014 & 2.03 & 3.62 \\
& 5.20 & 1.016 & 1.97 & 3.51 \\
& 6.00 & 1.034 & 2.08 & 3.71 \\
& 7.00 & 1.006 & 1.89 & 3.37 \\
\hline
\end{tabular}

a) $f=0.0562, V=200 \mathrm{ml} ; A=\pi \times 2.15^{2}\left(\mathrm{~cm}^{2}\right), L=0.0086 \mathrm{~cm}$ in equation (2)

$$
\begin{aligned}
& \frac{d C}{d t}=k\left(C_{0}-C\right)=\frac{S}{V} K_{\mathrm{T}}\left(C_{0}-C\right)=\frac{S}{V} \frac{D}{\delta}\left(C_{0}-C\right) \\
& \delta=1.612 \times D^{1 / 3} \times \nu^{1 / 6} \times \omega^{-1 / 2}
\end{aligned}
$$

where $C$ is the concentration at the time $t, C_{0}$ the saturated concentration, $k$ the rate constant, $K_{\mathrm{r}}$ the dissolution rate constant, $D$ the diffusion constant, $\delta$ the diffusion layer thickness, $v$ the kinematic viscosity and $\omega$ the angular viscosity of rotation.

The result is shown in Table $V$. The interaction coefficient, i.e., the ratio of the diffusion coefficient through membrane to that in water was given as 0.453 .

TABLE V. Diffusion Constants Evaluated from the Dissolution Rate Constant by Rotating Disk Method and from the Permeability Constant through

\begin{tabular}{|c|c|c|c|c|}
\hline \multirow[b]{2}{*}{ Run } & \multicolumn{2}{|c|}{ Dissolution method } & \multicolumn{2}{|c|}{ Permeation $\operatorname{method}^{a)}$} \\
\hline & $\begin{array}{l}K_{\mathrm{T}} \times 10^{3} \\
(\mathrm{~cm} / \mathrm{min})\end{array}$ & $\begin{array}{c}D \times 10^{6} \\
\left(\mathrm{~cm}^{2} / \mathrm{sec}\right)\end{array}$ & $\begin{array}{c}P \times 10^{7} \\
\left(\mathrm{~cm}^{2} / \mathrm{sec}\right)\end{array}$ & $\begin{array}{c}D \times 10^{6} \\
\left(\mathrm{~cm}^{2} / \mathrm{sec}\right)\end{array}$ \\
\hline 1 & 2.00 & 7.92 & 2.06 & 3.66 \\
\hline 2 & 2.07 & 8.32 & 2.10 & 3.73 \\
\hline \multirow[t]{2}{*}{3} & 2.10 & 8.48 & 2.14 & 3.80 \\
\hline & & 8.24 & mean $\langle D\rangle$ & $>3.73$ \\
\hline
\end{tabular}
Cellulose Membrane of Levomepromazine Maleate at $30^{\circ}$

a) See the value in Table III.

Acknowledgement The authors gratefully acknowledge the award of Research Grants from Naito Foundation (to T.N.). Thanks are also given for the generous supports of the materials to Banyu Pharmaceutical Co., Ltd., Daiichi Pharmaceutical Co., Ltd., Dainippon Pharmaceutical Co., Ltd., Nippon Squibb Co., Ltd., Sumitomo Chemical Co., Ltd., and Yoshitomi Pharmaceutical Co., Ltd. 